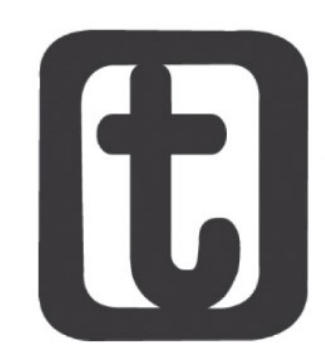

\title{
OS DESDOBRAMENTOS DO ETHOS IDEALISTA-FORMAL NO TRABALHO DOS/AS ASSISTENTES SOCIAIS
}

\author{
The idealist-formal ethos developments in the work of the social assistants
}

\author{
Jodeylson Islony Lima Sobrinho* \\ Rita de Lourdes de Lima**
}

\begin{abstract}
RESUMO
Esse trabalho apresenta parte dos resultados de dissertação de mestrado apresentada ao Programa de PósGraduação em Serviço Social da Universidade Federal do Rio Grande do Norte e objetiva desvelar os desdobramentos do ethos idealista-formal no trabalho dos/as assistentes sociais, fazendo assim uma mediação entre a formação e o exercício profissional. A amostra da pesquisa se deu com três discentes por Instituição (totalizando seis discentes); duas supervisoras de estágio por Instituição - acadêmica e de campo - portanto, quatro supervisoras, de duas Instituições de Ensino Superior da cidade de Teresina/PI, totalizando uma amostra de 10 entrevistas. Utiliza-se como técnicas: a pesquisa bibliográfica e documental, observação e entrevistas semiestruturadas. A análise dos dados aponta uma adesão formal ao Projeto Ético-Político Profissional, por parte de algumas das entrevistas, alinhada à posturas conservadoras. Tal dado sinaliza um crescimento do conservadorismo no âmbito da profissão e mostra uma relação com o recrudescimento do conservadorismo mundialmente na conjuntura atual.
\end{abstract}

\section{PALAVRAS-CHAVE}

Ethos idealista-formal. Serviço Social. Conservadorismo. ProjetoÉtico-Político.

\section{ABSTRACT}

This paper presents part of the results of a master's thesis presented to the Post-Graduation Program in Social Work of the Federal University of Rio Grande do Norte and it aims to unveil the unfolding of the idealistic-formal ethos in the work of social workers, it seeking to establish a mediation between training and professional practice. The sample of the research occurred with three students per Institution (totaling six students); two internships supervisors per institution - academic and field - therefore, four supervisors from two higher education institutions in the city of Teresina/PI, totaling a sample of 10 interviews. The techniques used are: bibliographic and documentary research, observation and semi-structured interviews. The analysis of the data indicates a formal adherence to the Professional Ethical-Political Project, by some of the interviewed, in line with conservative positions. This indicates a growth of conservatism within the profession and shows a relation with the resurgence of conservatism worldwide in the current conjuncture

\footnotetext{
* Assistente Social. Mestre em Serviço Social. Doutorando em Serviço Social pela Universidade Federal do Rio Grande do Norte (UFRN). Assistente Social da Universidade Federal de Mato Grosso do Sul. Coordenador de Pós-Graduação da Faculdade Adelmar Rosado (FAR). R. Prof. José Amável, 357, Cabral, Teresina (PI), CEP.: 64000-550. ORC ID: <https://orcid.org/0000-0002-0153-3920>. E-mail: <isllony@hotmail.com>.

** Assistente Social. Doutora em Serviço Social. Pós-Doutora pela Universidade Federal do Rio de Janeiro. Professora do Departamento e do Programa de Pós-Graduação em Serviço Social da UFRN. Av. Sen. Salgado Filho, 3000, Candelária, Natal (RN), CEP.: 59064-741. ORC ID: <https://orcid.org/0000-0002-7920-115X>. E-mail: <rita.pires2@gmail.com>.
}

DOI 10.22422/temporalis.2018v18n36p28-44 


\section{KEYWORDS}

Ethos idealist-formal. Social Work. Conservatism. Ethical-Political Project.

Submetido em: 30/9/2018.

Aceito em: 12/12/2018.

\section{INTRODUÇÃO}

A revitalização do conservadorismo na atual cena contemporânea é evidente, haja vista a vivência de tempos que beiram o irracionalismo teórico-político dos fundamentos da realidade social. Tal fato tem rebatimentos em nível de formação profissional e passa a preocupar o direcionamento das respostas dadas às demandas que chegam a tal profissional nas relações socioprofissionais. Refletir sobre o trabalho do/a assistente social no âmbito dessa sociabilidade significa apreender as tendências presentes nesse processo, que perpassa desde as implicações do ethos ${ }^{1}$ conservador até as implicações do ethos progressista, na perspectiva da emancipação humana.

Dessa forma, trazemos aqui um tópico da nossa dissertação, apresentando a discussão sobre o lugar que o pensamento conservador ocupa nos processos de trabalho e na formação profissional em Serviço Social, já que este, por sua vez, é permeado por uma pluralidade teórico-política que se autodetermina e autoimplica no conjunto da sociedade contemporânea e nos meandros dessa categoria.

Assim, apreender os determinantes sócio-históricos que conformam a constituição do ethos conservador no trabalho dos/as assistentes sociais e como esses, na sua formação/exercício profissional, se relacionam com esse ethos, foi o objetivo desse trabalho, que é fruto da dissertação de Mestrado em Serviço Social na Universidade Federal do Rio Grande do Norte (UFRN) ${ }^{2}$. Como percurso metodológico desse estudo utilizamos pesquisa bibliográfica e documental, observação e entrevistas semiestruturadas. Como lócus de pesquisa optamos por duas Instituições de Ensino Superior (IES), da cidade de Teresina/PI, que possuem o curso de Serviço Social ${ }^{3}$ e delineamos a quantidade de 10 (dez) entrevistadas (supervisoras de campo e acadêmica e estagiárias).

Para apresentar nossos argumentos organizamos esse trabalho em alguns tópicos para melhor apreensão pelos/as leitores/as: no primeiro momento, apresentamos suscintamente a discussão sobre o conservadorismo e seu recrudescimento no momento atual; a seguir discutimos os desdobramentos do ethos conservador no trabalho dos/as assistentes sociais, a partir da relação que se dá entre o fatalismo e messianismo profissional; e, por fim, apresentamos algumas aproximações inicias desses desdobramentos para/na profissão.

${ }^{1}$ Ethos aqui compreendido como o modo de ser dos sujeitos, a forma como dão materialidade ao conjunto de princípios e valores - objetiva/subjetivamente - no conjunto das relações sociais; é a forma como direcionam suas escolhas e, diante disso, como se colocam frente aos pores teleológicos desencadeados por essas escolhas. Ou seja, é a identidade social, que se move no campo dialético da relação entre a universalidade (humanidade) e a singularidade (individualidade).

${ }^{2}$ A dissertação teve como título: Construindo hoje, o amanhã desejado: Os Ethe Político-Profissionais dos/as Assistentes Sociais - entre rupturas, continuidades e tensões contemporâneas , foi defendida em 2016, e contou com bolsa demanda social do Conselho Nacional de Desenvolvimento Científico (CNPq).

${ }^{3}$ As instituições foram as seguintes: Universidade Federal do Piauí (UFPI) e Faculdade Adelmar Rosado (FAR).

Temporalis, Brasília (DF), ano 18, n. 36, p. 28-44, jul./dez. 2018. ISSN 2238-1856 
No processo investigativo, por ter se desenvolvido diretamente com seres humanos, fizemos jus à Resolução do Conselho Nacional de Saúde n. 466/2012, a qual trata das Diretrizes e Normas Regulamentadoras de Pesquisa envolvendo seres humanos respeitando, assim, o sigilo dos sujeitos da pesquisa, adotando os referenciais básicos da bioética. Respeitamos as normas estabelecidas na Declaração de Helsinki (1975, revisada em 1983, 1989, 1996, 2000, 2002, 2004, 2008 e 2013). Nesse sentido, a pesquisa foi submetida ao Comitê de Ética da UFRN sob o processo n. CAAE: 43773615.7.0000.5292 e aprovada sob o parecer n. 1.375. 368 .

\section{MODERNIDADE E CONSERVADORISMO}

A modernidade - período histórico que começa com o renascimento na Europa Ocidental, com uma série de transformações sócioestruturais e intelectuais profundas - inaugurou um novo imaginário reflexivo e crítico. Tal período nasce junto com a sociedade capitalista, pois à uma nova forma de organização da produção no mundo, também corresponderá uma nova forma de organizar o conjunto de ideias.

A construção do mundo moderno se deu fundamentada nas ideias iluministas de igualdade, liberdade, autonomia, secularização, racionalização e emancipação humana que visavam romper com o padrão dominante feudal-teocrático, com o surgimento da sociedade burguesa.

A burguesia não pode sobreviver sem revolucionar constantemente os instrumentos de produção, e com eles as relações de produção, e com eles todas as relações sociais. [...] Revolução ininterrupta da produção, contínua perturbação de todas as relações sociais, interminável incerteza e agitação, distinguem a era burguesa de todas as anteriores. [...] Todas as relações fixas, enrijecidas, com seu travo de antiguidade e veneráveis preconceitos e opiniões, foram banidas; todas as novas relações se tornam antiquadas antes que cheguem a se ossificar. Tudo o que é sólido desmancha no ar, tudo o que é sagrado é profanado [...] (MARX, 1848, p. 3).

Nesse momento de construção dessa nova ordem social, a burguesia encontrou forte resistência do pensamento conservador clássico, uma vez que tal pensamento desejava o retorno do mundo feudal e de sua forma de organização. Desse modo, o pensamento conservador clássico nasce já na sociedade Capitalista, inicialmente, como um olhar voltado para o passado, desejando a volta da sociedade feudal.

O termo conservador foi usado pela primeira vez por Visconde de Chateaubriand (17681848), para denominar o periódico que publicava para difundir as ideias de restauração clerical e política, ou seja, naquele período, o termo significava uma reação à Revolução Francesa e à queda do antigo regime. Com o tempo, o termo passou a ser amplamente usado na Alemanha a partir de $1830^{4}$ e foi oficialmente adotada na Inglaterra em 1835 (NISBET, 1981).

\footnotetext{
${ }^{4}$ Assinale-se que foi também a partir de 1830-1848 que o pensamento e a razão burguesa entram em seu período de decadência ideológica, conforme denunciado por Marx e analisado por Lukács, ou seja, o pensamento burguês que antes desse período se preocupava em desvelar a realidade e conhecê-la
}

Temporalis, Brasília (DF), ano 18, n. 36, p. 28-44, jul./dez. 2018. ISSN 2238-1856 
Nesse momento inicial o pensamento conservador desejava a volta da hierarquia, estabilidade e privilégios feudais e por isso, tal forma de pensar encontrou enorme simpatia junto aos membros do clero católico, que se posicionou firmemente contrário aos ideais do iluminismo e da modernidade: a laicização do Estado, o racionalismo excessivo, o poder civil, o socialismo, o naturalismo, o humanismo (o ser humano como centro do mundo), o liberalismo (separação da Igreja e Estado, laicização das instituições, igualdade dos cultos perante a lei), o individualismo, o secularismo e igualitarismo e o desrespeito as autoridades da sociedade moderna (NISBET, 1981).

Contudo, a burguesia, inicialmente classe revolucionária e, portanto, portadora de valores também revolucionários e emancipatórios ${ }^{5}$, chega ao poder e torna-se classe dominante. A esse processo de transmutação da burguesia de classe revolucionária para classe dominante, também se soma o processo de modificação do pensamento conservador clássico, que de defensor da sociedade feudal, passa a defensor do status quo.

Desse modo, o pensamento conservador, inicialmente profundamente ligado a defesa de uma ordem clerical, vai modificando sua função sociopolítica. De profundo crítico da nova ordem, se torna defensor da mesma, mantendo presente, contudo, a maioria dos traços elencados anteriormente, "[...] o único deles que, no pós-48, tenderá a perder sua importância é o componente clerical, cada vez menos visível” (ESCORSIM NETTO, 2011, p. 67 , grifos originais $)^{6}$. Desse modo, o pensamento conservador moderno não mais deseja a volta da sociedade feudal teocrática, hoje, o termo designa comumente "[...] uma disposição ou tendência para preservar o que está estabelecido [...]” (NISBET, 1981, p. 62), estando geralmente associado à defesa da ordem e do status quo. Nesse processo de readaptação/readequação/refuncionalização do pensamento conservador, nasce o pensamento conservador moderno. Desse modo, após 1848, podemos afirmar que o pensamento conservador deixa de ser clássico e se torna moderno e passa, nesse processo de mudança, a defender a manutenção e estabilidade da sociedade capitalista.

Para os defensores do pensamento conservador, os indivíduos têm necessidades inalteráveis que são: a ordem, a religião, a tradição, a família e a segurança. Nesse sentido, todos os governos devem priorizar esses elementos fundamentais na gestão da sociedade. Desse modo, o pensamento conservador, ao longo da história, vai se metamorfoseando, mas sempre se dá baseado nos pressupostos elencados acima. Noutras palavras, tenta-se convencer a todos que qualquer tentativa de mudar a sociedade é prejudicial, inútil ou desastrada. Inúmeros são os exemplos ao longo da história, mas ressalte-se, a título de ilustração, a resistência dos grupos conservadores ao voto feminino, ao ingresso das mulheres no mercado de trabalho, a abolição da escravatura, entre outros (HIRSCHMAN, 1992; TOSCANO; GOLDENBERG 1992).

verdadeiramente, passa a partir de então a desempenhar uma função apologética e justificadora da sociabilidade burguesa (Cf. NETTO, 1981).

${ }_{5}^{5}$ Assinala-se como elementos progressistas do pensamento moderno: o humanismo, o pensamento críticodiáletico, o historicismo e a construção do conhecimento tendo como referência a busca da verdade numa perspectiva ontológica.

${ }^{6}$ Assinala-se que o pensamento conservador afastou-se da defesa da ordem clerical como poder que deve organizar a sociedade. Ou seja, o pensamento conservador vai continuar a enfatizar que, mais que a razão, o sentimento, a emoção e o sagrado são fundamentais a vida humana em sociedade (Cf. ESCORSIM NETTO).

Temporalis, Brasília (DF), ano 18, n. 36, p. 28-44, jul./dez. 2018. ISSN 2238-1856 
Na atualidade, o pensamento conservador tem recrudescido a passos largos. A crise do sistema capitalista mundial que se inicia em final dos anos 1970, na ânsia de encontrar explicações de outra ordem para os problemas gerados pelo próprio capitalismo, se espraia pelo mundo e coloca em questionamento uma série de ideias, valores e pressupostos da modernidade. Como resposta a tal crise, a burguesia inicia o processo de reestruturação produtiva7, refuncionando o capitalismo mundial, por meio do toyotismo e uma precarização crescente no mundo do trabalho, por meio de exigências cada vez maiores de produtividade e rapidez. Ao mesmo tempo, em que se enxuga a máquina estatal com cortes no âmbito das políticas sociais em geral.

Surge, entre outros elementos, o chamado Pós-modernismo, que se enraíza na crise do sistema econômico mundial e tem como pressupostos o questionamento a todas as grandes narrativas, a celebração do subjetivismo, da desconstrução, do micro, do pontual e fragmentado, reafirmando os sentimentos em detrimento da racionalidade ${ }^{8}$. Em algumas posturas, influenciadas por tal pensamento, predomina o antiteoricismo, o pragmatismo extremo, o empiricismo, a dicotomia teoria x prática, entre outros elementos.

Essa onda pós-moderna que se disseminou em todas as áreas do conhecimento, também se disseminou no senso comum e na sociedade, levando a uma revalorização do sagrado, dos sentimentos, do momento presente, do pragmatismo e da religiosidade em geral. De fato, assiste-se em todos os continentes ao recrudescimento de movimentos e partidos de extrema direita, que pregam a xenofobia9', a LGBTfobia, o racismo, a intolerância religiosa e todas as formas de discriminações, baseados na ideia que o meu grupo, meu país, minha raça, minha religião e minha orientação sexual são as corretas e todos os outros que não participam do meu grupo não têm os mesmos direitos que eu.

O pensamento conservador-religioso tem avançado no Brasil ${ }^{10}$ e no mundo a uma velocidade assustadora e a falta de conhecimento sobre a história humana, suas lutas, seus avanços e retrocessos tem sido um campo fértil ${ }^{11}$ para o retorno de velhos argumentos que pareciam já superados, como a ênfase ao perigo de destruição da família - que outrora foi

\footnotetext{
${ }^{7}$ A reestruturação produtiva caracteriza-se, entre outros elementos, pela acumulação flexível, a qual se estrutura conformando uma nova organização de trabalho (Toyotismo), que intensifica as condições de exploração da força de trabalho, mas sob a aparência de colaboração e trabalho em equipe. Tal forma de trabalho também sustenta as bases de sedimentação do neoliberalismo. Ver, entre outros, Antunes (1998).

8 O movimento Pós-moderno é complexo e amplo, tendo em seu interior diversas perspectivas, inclusive do ponto de vista político. A bibliografia acerca desse movimento é vasta e rica. Limitamo-nos remeter a um clássico sobre o assunto: Harvey (1993).

${ }_{9}^{9}$ Alguns autores já questionam o uso do termo Xenofobia que significa ódio por pessoas estranhas àquele meio, geralmente ao estrangeiro migrante. Contudo, o ódio não é contra todo estrangeiro, mas somente aos estrangeiros pobres, portanto, o ódio é ao estrangeiro pobre, que migra na luta pela sobrevivência. Nesse sentido, é um ódio dirigido aos setores mais empobrecidos da classe trabalhadora, sendo, portanto, uma questão de classe social.

${ }^{10} \mathrm{O}$ Brasil é o país que mais mata a população transexual no mundo. Em 2008, foram 486 mortes, número quatro vezes maior que o país que ocupa o segundo lugar no ranking (ALMEIDA, Guilherme (UERJ). Fala no Seminário Nacional Serviço Social e identidade trans, realizado pelo Conselho Federal de Serviço Social, dias 11 e 12 de junho de 2015, em São Paulo).

"É fato inconteste que a internet com sua rápida possibilidade de difusão de informações facilitou o acesso da população as mesmas, contudo, pelo mesmo movimento, possibilitou também acesso a informações, por vezes, superficial, equivocada, reproduzindo preconceitos e fundamentalismos.
}

Temporalis, Brasília (DF), ano 18, n. 36, p. 28-44, jul./dez. 2018. ISSN 2238-1856 
usado como argumento contrário ao voto feminino e ao ingresso das mulheres no mercado de trabalho - hoje utilizado contra o casamento entre casais homossexuais. Do mesmo modo, o pensamento conservador atual ressalta, continuamente, que tais mudanças podem desencadear o caos social.

O que se constata a partir desses dados é que o pensamento conservador voltou com toda força e os tempos contemporâneos mostraram-se propícios ao seu ressurgimento e proliferação. Precisamos, portanto, estar atentos a essas manifestações do pensamento conservador, para resistir e criar caminhos que busquem a plena emancipação e liberdade humana.

\title{
O ETHOS CONSERVADOR NO TRABALHO DOS/AS ASSISTENTES SOCIAIS
}

Verifica-se que tal pensamento, se entranha nas relações profissionais, o qual permite um processo que subsume as demandas socioprofissionais à sua dimensão institucional, pois ao analisar o conjunto complexo das determinações do real, reduzindo- o à uma única expressão, se está restringindo as possibilidades de apreensão da totalidade social e, por conseguinte, a possibilidade de superar uma intervenção profissional fatalista e pragmática.

Nas entrevistas realizadas, percebe-se um processo de retomada ora do metodologismo/tecnicismo; ora de um teoricismo acrítico; ou de um pragmatismo imediato, quando não, de um voluntarismo, ou seja, nota-se uma certa referência ao espectro da ajuda ${ }^{12}$, e que, (in)diretamente, retoma aspectos tidos como vencidos no Serviço Social, sobretudo, àqueles ligados aos princípios e valores da Igreja Católica. Outro dado importante, que precisa ser retomado aqui, são os projetos de intervenções das estagiárias, as quais legitimam tanto os valores institucionais, como também acabam assumindo responsabilidades institucionais que deveriam ser próprias do Estado, reforçando a lógica da refilantropização da ação estatal, próprio do processo de neoliberalização ${ }^{13}$ contemporâneo. Esta questão verifica-se nessa fala:

\begin{abstract}
Aí o Serviço Social bater de frente com o Estado é muito complicado, entendeu? Assim, falando não em termos científicos, mas o que eu vejo lá. Porque, eu mesmo, meu Projeto de Intervenção foi a questão da brinquedoteca. A brinquedoteca foi realizada com outra aluna que é estagiária lá, nós duas conseguimos várias doações, mas o Estado não doou, entendeu? Quem doou, quem se sensibilizou foi a diretora da penitenciária que doou algumas coisas para a brinquedoteca, que ela nos ajudou, nos auxiliou, mas é muito complicado, principalmente por ser terceirizado, né? (E5, 26a, ESTAGIÁRIA).
\end{abstract}

Não podemos deixar de considerar as condições concretas em que se dá o trabalho na

\footnotetext{
${ }^{12} \mathrm{O}$ espectro da ajuda aparece com certa frequência nas falas das sujeitas, sobretudo, no direcionamento dado na intervenção profissional, o que nos parece haver uma retomada dos subsídios profissionais alinhados à perspectiva do paternalismo e da tutela dos/as usuários/as. Tal contexto, acaba por subtrair as determinações substantivas do nosso Projeto Ético-Político Profissional, que se direciona na/pela emancipação política e humana desses sujeitos.

13 Por neoliberalismo entendemos a reação do capital contra o modelo keynesiano-fordista, com a recuperação dos postulados liberais, cujo eixo principal evidentemente é a priorização e referência ao mercado como ponto de partida e de chegada para todos os valores econômico-sociais. Tem como principal proposta a diminuição da ação do Estado no campo das políticas sociais. Ver a esse respeito, entre outros Sader e Gentili (2010).
} 
contemporaneidade, o que nos conduz a refletir sobre o quanto essas condições interpelam os processos de trabalho do/a assistente social, pois como qualquer outro/a trabalhador/a, ele/ela também se insere na divisão do trabalho, a partir de uma especialização e por meio da venda da sua força de trabalho, que é regulada por formas distintas de contrato. Portanto, esse/a profissional viverá os dilemas da alienação e as determinações sociais que acometem a coletividade dos/as trabalhadores/as.

Então, diante da fala exposta anteriormente, podemos observar que o Serviço Social na instituição assume características concretas do processo de precarização operado no mundo do trabalho, quando temos, nesse caso, uma inserção por meio da terceirização do trabalho, realocando determinações próprias para tal forma de contrato, o qual incide diretamente na autonomia profissional, delineando formas específicas de intervenção profissional, condizendo com os interesses institucionais.

Entretanto, por mais difícil que seja a correlação de forças num determinado espaço profissional, a própria dialética presente nas relações sociais, nos deixa sempre uma certa margem, às vezes mínima, para a transgressão dos limites postos pelos empregadores. Partindo desse pressuposto, lamamoto (2014, p. 219) nos coloca a necessidade de:

Resguardar a relativa autonomia na condução do exercício profissional [e] potencializá-la mediante um projeto profissional coletivo impregnado de história e embasado em princípios e valores radicalmente humanistas, com sustentação em forças sociais reais que partilham de um projeto comum para a sociedade (IAMAMOTO, 2014, p. 219).

Corroborando, ainda, com as condições concretas que se colocam no cotidiano profissional, também há um discurso que busca fazer o que se precisa fazer para ajudar os indivíduos, mesmo que tais ações estejam no campo do empreendedorismo, empoderamento, retomando a dimensão de responsabilização da sociedade para gerir suas próprias demandas, o que leva a um conjunto de práticas profissionais distorcidas, caóticas, fragilizadas, e, até mesmo, vazia de significados, contribuindo - em sua maioria para a perpetuação da reprodução de um ciclo vicioso de paternalismo-subjetivista ${ }^{14}$.

Então, as próprias alterações no contexto da realidade atual trouxeram um processo de aprofundamento da decadência ideológica, ética e política no campo mais geral da sociedade, o que impacta diretamente na profissão de Serviço Social, ou seja, passa-se também a dar respostas imediatas e superficiais no âmbito do exercício profissional.

Dessa forma, nesse contexto de recrudescimento do conservadorismo tem-se uma forte tendência do/a assistente social redimensionar sua demanda socioprofissional subsumindo-a à demanda institucional, donde qualquer método de análise do real é tido como válido, caindo no campo do relativismo metodológico, o que incide também em um processo de relativismo ético e político, que nos termos de Pontes (2010):

\footnotetext{
${ }^{14}$ Por paternalismo subjetivista entendemos uma determinada forma de ação profissional que contribuem para tutelar os usuários aos sujeitos profissionais, reproduzindo assim, um ciclo de responsabilização desses profissionais em relação a seus usuários, conformando laços de dependência e autoridade sobre os tutelados, frequentemente baseadas no senso comum e com um forte conteúdo subjetivista.
}

Temporalis, Brasília (DF), ano 18, n. 36, p. 28-44, jul./dez. 2018. ISSN 2238-1856 
Aparece ao intelecto do profissional despida de mediações, parametrada por objetivos técnico-operativo, metas e uma dada forma de inserção espacial (bairro, município etc), programática (divisão por projetos ou áreas de atuação) ou populacional (crianças, idosos, migrantes etc). Numa palavra, a demanda institucional aparece peiada à imediaticidade, com um 'fim em si mesma' (PONTES, 2010, p. 168).

É perceptível nas falas das entrevistadas que elas se amparam categoricamente, diria abstratamente nos valores e princípios do atual projeto ético-político, numa perspectiva democrática, cidadã, o que coloca em pauta uma discussão acerca do esvaziamento do conteúdo político efetivo dessas categorias analíticas no conjunto da categoria profissional.

Sendo assim, percebe-se que há um verdadeiro abismo teórico-político entre os valores conclamados, pelo menos como discurso, por parte significativa dos/as profissionais - e ditos, por eles/elas, como bases de sua atuação profissional - e os valores efetivamente empreendidos por eles/elas que emanam do dia-a-dia profissional. Como bem apontamos anteriormente, parece que o discurso tem se tornado cada vez mais vazio, limitando-se a grandes jargões no âmbito da profissão.

$\mathrm{E}$, nessa perspectiva também se encontra um processo de hipervalorização da efemeridade, tendo em vista que o/a assistente social, em um curtíssimo espaço de tempo, deve garantir a operacionalidade de seu serviço, relegando à último plano a sua condição de acionar as mediações necessárias para tal funcionalidade, recaindo na análise superficial e simplista da realidade, reforçando a lógica de intervenções que atendam meramente aos interesses institucionais. Isso é confirmado quando as entrevistadas falam sobre a questão da autonomia profissional ou da relação teoria/prática, assinalando a dificuldade que têm de ir além das demandas institucionais mais imediatas - o que pode ser percebido tanto na fala da profissional, supervisora de campo, quanto na da estagiária, ainda em processo de formação:

\begin{abstract}
Por exemplo, eu tenho duas instituições que as próprias profissionais chegam para mim e falam: 'Eu não tenho autonomia', né? Eu questiono uma intervenção, por exemplo, uma intervenção que poderia ser ampliada. - 'Olha, isso está acontecendo aqui, tal e tal, a minha estagiária percebeu isso. Existe algum programa que você pode inserir?' Aí, ela olha para mim, sorri e fala: 'existe, mas eu tenho que pedir autorização, eu não tenho autonomia, nenhum projeto que a gente realiza pode ser nosso, o projeto é da instituição e existe um controle muito grande da coordenação, não sai sem o aval da coordenação. Somos barradas totalmente, totalmente retirada a autonomia' (SA ${ }^{15} 1$, 47a, 12 a/FORMADA)

Tem a questão da teoria e prática. É muito fácil quando a gente está numa sala de aula, a gente ter a noção 'olha, o serviço social deve dar tal resposta para tal questão social', só que na prática mesmo a gente ver um... não há um distanciamento muito grande, mas há um distanciamento. (E2, 20a, ESTAGIÁRIA)
\end{abstract}

Destarte, salientamos a velha questão própria do pensamento conservador, consubstanciada pela tradição positivista e seus derivados, que é a disjunção teoria e prática. Parece-nos que tal entrave já foi superado pelo conjunto das sistematizações teóricas que temos nesse limiar, entretanto, tal discurso, muito presente no senso comum e na ciência positivista em geral, que separa a reflexão da execução, se esmiúça e impregna

${ }^{15}$ SA - Supervisora Acadêmica.

Temporalis, Brasília (DF), ano 18, n. 36, p. 28-44, jul./dez. 2018. ISSN 2238-1856 
o imaginário social, e coloca-se como explicação mais imediata para os desafios e impasses da realidade institucional.

Desse modo, todas as dificuldades e impasses da realidade institucional encontram sua explicação, aparentemente satisfatória, na frase a teoria é uma coisa e a prática é outra, o que demonstra uma análise superficial da realidade, que não consegue analisar os determinantes sociais, nem estabelecer as devidas mediações, a fim de propor ações adequadas diante de tais desafios.

Quanto mais submerso estiver o /a profissional em seu cotidiano profissional, mais se torna evidente as contradições imanentes nessa realidade, campo propício de sustentação e propagação do ethos conservador, pois nessa lógica é cômodo a defesa da moral capitalista, donde a regressão dos princípios e valores contidos no nosso código de ética é expressão máxima dessa realidade, a exemplo do fortalecimento do pragmatismo e de um moralismo barato das expressões da questão social.

Há, com isso, uma inquirição do pensamento conservador sobre o caráter ontológico da realidade, ao qual segundo Guerra (2011) busca transformar "[...] a razão moderna, objetiva e dialética num produto das consciências individuais, ou, no limite, em uma camisa de força dos sujeitos" (GUERRA, 2011, p. 56-57). Isso tem levado a uma intervenção políticoprofissional caótica, distorcida de seus reais fundamentos, adquirindo um alto nível de legitimidade perante as condições estruturantes do cotidiano profissional, quando, por exemplo as profissionais realizam sua prática profissional, como sendo algo que depende da subjetividade de cada profissional. A fala a seguir demonstra, significativamente, tal postura: "Pelo fato de ser seis profissionais, é muito diferente o fazer de uma para outra. O serviço social não tem uma cara, e aí cada uma tem seu jeito do fazer profissional” (E1, 22a, ESTAGIÁRIA).

Acerca disso, Barroco e Terra (2012, p. 68) pontuam que:

É comum o entendimento de que os pressupostos valorativos que servem de orientação para o julgamento das ações éticas podem variar de acordo com os valores pessoais dos indivíduos. Essa ideia concorre para uma relativização da ética e para uma visão que perpassa pelo pensamento social reproduzido pelo senso comum: a visão de que cada um tem a sua moral e a sua ética, desconectadas das suas determinações sociais, e/ou o entendimento de que elas decorrem da subjetividade dos indivíduos, não dispondo de determinações objetivas (BARROCO ; TERRA, 2012, p. 68).

Ao subsumir a prática profissional à dimensão subjetiva, relegando-a ao fazer singular de cada profissional, tem-se aí uma forte tendência conservadora, o que compreende uma ausência de análises concretas da realidade, pautadas no conjunto das determinações teórico-práticas sistematizadas no âmbito do Serviço Social brasileiro, em sua perspectiva crítica.

O trabalho, então, passa a operar por si mesmo, o qual controla os sentimentos do próprio sujeito, e, dessa maneira, a subjetividade assume um papel de mero executor de intervenções institucionais, demarcando uma ruptura entre as bases ontológicas do ser social, aqui como profissional, e sua própria consciência. Tais tendências profissionais encontram um verdadeiro acento na racionalidade abstrato-formal, constituída e

Temporalis, Brasília (DF), ano 18, n. 36, p. 28-44, jul./dez. 2018. ISSN 2238-1856 
constituinte na/da forma de pensar da sociabilidade do capital, em sua perspectiva conservadora.

Percebe-se também que existe um processo de individualização do ser social, reduzindo-o à condição de um ser individual, o que no âmbito das profissões adquire uma certa conotação pelo reforço da valorização do hábito/comportamento como forma de intervir na realidade, o que recai na desvalorização de uma cultura crítica sobre os fundamentos da realidade, numa direção mais coletiva, direcionada pelos valores e princípios hegemônicos da profissão. Mais uma vez, recai-se na discussão teoria/prática e reforça-se o fatalismo/pragmatismo, como único caminho possível para quem está na prática:

\begin{abstract}
O olhar, a realidade. Eu achei da minha formação, quer da leitura, da teoria, é totalmente diferente da prática, da realidade. Eu acho isso, e aí eu busco mais a prática. Eu fico observando o que a assistente social faz, que é uma coisa totalmente diferente da teoria, porque a realidade é complicada. Porque há coisas que na teoria tem assim, que a gente vê, que não cabe ali na prática, é uma coisa assim, que às vezes a gente age por emoção, a gente age diferente, a gente vê que é totalmente diferente da teoria (E4, 22a, ESTAGIÁRIA).
\end{abstract}

A reatualização do pragmatismo é uma forte tendência na cena contemporânea, o que é perceptível pelo conjunto de falas aqui expostas, tendência essa que leva à constituição de uma perspectiva de reforçar o Serviço Social como uma tecnologia social, uma profissão meramente pragmática, "[...] de modo que a profissão parece resultar do casual, do aleatório, do caótico, do improviso, respondendo às demandas inespecíficas" (GUERRA, 2014, p. 49).

A prática, portanto, parece autonomizar-se da dimensão do conhecimento, ou de outra forma, parece que o conhecimento teórico não faz sentido diante da prática profissional, o que leva ao discurso inverídico de que na prática a teoria é outra. Nesse sentido, o conhecimento, segundo Guerra (2011):

[...] passa a ser um conjunto de conceitos discriminados que representem coisas, apartadas e individualizadas entre si, a partir das quais os indivíduos concebem a realidade e cristalizam-se, tanto pelo hábito quanto pela reincidência dos problemas com os quais o profissional se defronta (GUERRA, 2011, p. 171).

Enquanto por um lado percebe-se um processo de ultravalorização do fatalismo/pragmatismo, quando por exemplo nas falas algumas sujeitas pontuam que "[...] fazem aquilo que podem [...]" (E1, 22a, ESTAGIÁRIA), por outro lado também se percebe uma reatualização daquilo que lamamoto (2013) apontou como a perspectiva messiânica do Serviço Social, reforçada pelo fantasma da ajuda, ainda bastante presente nos contornos da profissão. Afirmar que o Serviço Social se assenta em uma dimensão messiânica é centralizar nos/as assistentes sociais a resolutividade para todos os problemas e demandas que chegam no cotidiano das relações socioprofissionais, o que desconsidera as determinações societárias, institucionais e profissionais que a engendram.

Dito isso, também se pode observar nas entrevistas realizadas a forte tendência dessa visão messiânica da profissão, responsabilizando-a por um conjunto de ações que não cabem à uma profissão, isoladamente:

Não, pelo que eu vejo lá, quando tem uma coisa que é impossível, a gente (Serviço Social) dá um jeito [...] Em relação também a documentos, tudo essas coisas, a 
gente dá um jeito [...] O Serviço Social é... eu, pra mim, lá no Centro POP é uma mãe, as pessoas confiam mais na gente pra conversar (E4, 22a, ESTAGIÁRIA).

O estágio é fundamental, realmente é onde a gente aprende. Onde a gente tá ali com a mão na massa, que a gente vê a realidade, que a gente tem que ajudar e procurar os meios pra ajudar a pessoa (E3, 34a, ESTAGIÁRIA).

Diante das falas das entrevistadas, podemos afirmar que essa tendência pragmática/messiânica de parte das profissionais se consubstancia na inter-relação entre conferir um conjunto de responsabilidades à profissão, que não cabe a ela mesma resolver - ao menos na sua dimensão particular - e, diante disso, dar respostas a essas demandas, a partir de uma vocação que coloca a ajuda no centro dessa realidade.

Porquanto, tais falas reforçam uma lógica de recolocar no Serviço Social a perspectiva de que a escolha por essa profissão tem se dado por uma vocação, que se fez o curso de Serviço Social simplesmente porque se gosta de ajudar as pessoas. Há, ainda, falas que dizem que a pessoa já era quase uma assistente social, por isso acabou fazendo o curso para legitimar uma prática que já fazia na sua comunidade, igreja, ONG, instituição que trabalhava, dentre outras. Tal discussão já apresentada em outros momentos por Guerra (2014, p. 47) mostra o quanto essa vertente está presente nos contextos da formação e do exercício profissional, quando o Serviço Social, por vezes:

[...] é identificada com vocação, prática de ajuda e/ou militância, pautada em valores anti-capitalistas românticos e humanista-cristão. Assim, dos espaços sócio-ocupacionais recebe o imperativo: 'Faça ou não será considerada compromissada'. Apoiada num eticismo, que supõe que as condições objetivas da realidade possam ser subsumidas ao 'compromisso' e à boa vontade da profissional, desencadeiam-se posturas voluntaristas e messiânicas que historicamente nos têm levado à incorporação gradativa de funções genéricas, demandas inespecíficas, meras atividades que não cabem a nenhuma profissão, sob o argumento conformista do 'afinal, não custa nada' (GUERRA, 2014, p. 47).

Mesmo passados quase 40 anos da ruptura com o Serviço Social conservador, o quanto o espectro da ajuda ainda ronda as atuais intervenções profissionais, a qual não se reduz a um número insignificante, pelo contrário, essa proposta interventiva aparece significativamente nos processos de trabalho dos/as profissionais, e, quando essa ajuda se configura nos valores humano-cristãos, a perspectiva que se tem é a de reatualização do conservadorismo, a qual tem seus fundamentos sustentados nos valores cristãos, como apontam as falas das seguintes entrevistadas:

Assim, os elementos que eu utilizo, que eu tenho na minha bagagem profissional é sempre ter um atendimento humanizado [...] o atendimento é individual, respeitar o próximo como se fosse eu (E5, 26a, ESTAGIÁRIA).

De você estar ali pronta para ajudar alguém, para orientar alguém, para acompanhar no caso das orientações, para beneficiar alguém em todos os aspectos que podemos (E3, 34a, ESTAGIÁRIA).

O estágio é fundamental, realmente é onde a gente aprende. Onde a gente está ali com a mão na massa, que a gente vê a realidade, que a gente tem que ajudar e procurar os meios para ajudar a pessoa (E4, 22a, ESTAGIÁRIA). 
Diante disso, afirmamos que a reatualização do conservantismo - em sua tendência messiânica - leva a um conjunto de contornos no modo de pensar e agir dos/as profissionais, recaindo na (re)configuração da cultura profissional, redimensionando-a a uma vertente que desqualifica a própria profissão, pois nessa lógica "[...] qualquer um pode fazer o trabalho do/a assistente social; vou fazendo tudo o que estiver ao meu alcance para poder ajudar o/a usuário/a; o Serviço Social é uma verdadeira mãe para os/as usuários/as dos serviços" (E4, 22a, ESTAGIÁRIA).

Tal realidade leva à adesão de intervenções profissionais com contornos imediatos e superficiais às demandas que aparecem, reduzindo-as às suas manifestações aparentes, sem levar em consideração a totalidade das determinações que as compõem, como aponta lamamoto (2013, p.27-28, grifos nossos):

[...] seu pensamento tende a aderir aos contornos imediatos da situação com que se defronta, valorizando os detalhes, os dados qualitativos, os casos particulares, em detrimento da apreensão da estrutura da sociedade. A mentalidade conservadora não possui predisposição para teorizar. Sendo a organização da sociedade vista como fruto de uma ordenação natural do mundo, o conhecimento visa a um controle prático das situações presentes (IAMAMOTO, 2013, p. 27-28, grifo nossos).

O que está em jogo nessa configuração profissional, nada mais é do que os caminhos que o atual Projeto Ético-Político trilhará nos anos subsequentes, exatamente porque na cena contemporânea, em que há um contingente de projetos societários em disputa, o que se observa é o avanço do ethos conservador no conjunto das relações sociais, expresso pela intolerância em todas as dimensões do ser social, pela apologia a um conjunto de valores e princípios antidemocráticos, sustentando a tese de reatualização desse conservantismo, em sua versão mais bárbara.

Essa perspectiva, ainda encontra um terreno fértil no campo teórico-prático dos direitos, visto haver uma hipervalorização desses, sobretudo, quando subsumido ao lastro das políticas sociais, a qual reflete a defesa/expressão da própria moral capitalista, reduzindo e/ou alinhando os princípios do Código de Ética Profissional (CEP) à estrutura capitalista dos direitos e das políticas sociais, o que coloca em pauta um estatuto legalista a esse instrumento, limitando-o à emancipação política da classe trabalhadora, como apontam algumas falas:

O projeto Ético Político [...] traz tudo aquilo de direitos humanos, e não sei o quê e tal... (E1, 22a, ESTAGIÁRIA).

Defender os direitos das meninas em si, já que os direitos delas estão violados... (E2, 20a, ESTAGIÁRIA).

Trabalhamos na garantia dos direitos e com o dever da cidadania. Então o Serviço Social lá, ele trabalha com essas ações e elas são de suma importância para o indivíduo no seu processo de reintegração social (E5, 26a, ESTAGIÁRIA).

Então, o que se observa é uma verdadeira apologia aos direitos, constituindo-se em verdadeiros jargões profissionais, donde parece que todo/a profissional de Serviço Social já está embutido em seu discurso da defesa por direitos, os quais muitas vezes não sabem sequer se tais direitos se alinham ao Projeto Ético-Político, ou até mesmo quais direitos eles/elas próprios/as defendem. Em muitas falas é notório que esses têm se direcionado 
mais para a via do favor, da ajuda e da benevolência - como já apontado anteriormente do que verdadeiramente como algo conquistado pela classe trabalhadora e que lhe pertence, enquanto socialização da riqueza produzida socialmente. Também não se analisa as limitações desses direitos assegurados, nem tampouco analisa-se as determinações sociais impostas pela lógica do capital a esses direitos.

É preciso termos clareza sobre qual a perspectiva de direito que defendemos. Os direitos são obras da própria sociabilidade do capital e são a outra face da desigualdade social, conforme analisam lamamoto e Carvalho (2014)

\begin{abstract}
O que merece ser ressaltado é que a sociedade do capital supõe uma contradição inevitável na sua continuidade: o discurso da igualdade e realização da desigualdade. De um lado a afirmação da liberdade individual e da igualdade de direitos e deveres de todos os cidadãos, como condição de funcionamento pleno da economia de mercado. [...] Em polo oposto, tem-se a desigualdade inerente à organização da sociedade como unidade de classes sociais distintas e antagônicas assentada em uma relação de poder e exploração (IAMAMOTO; CARVALHO, 2014, p. 97-98).
\end{abstract}

Contudo, ao mesmo tempo que reconhecemos nossos limites, é preciso entender a luta por direitos como tática nesse momento histórico e como meio limitado, mas necessário, para assegurar o que foi usurpado da classe trabalhadora.

Por conseguinte, torna-se necessário apreender os determinantes que compõem essa realidade, e, diante disso reafirmar a defesa desses, mas compreendendo seus limites e possibilidades, caso contrário, reforçaremos um ethos que nega a liberdade dos indivíduos. Nesse sentido, concordamos com Behring e Santos (2009) quando afirmam que:

[...] as lutas por direito nutrem de possibilidades o processo de socialização da política, ao tempo em que explicam seu limite, quando se constitui um tipo de universalidade abstrata no reconhecimento de sujeitos de direitos universais, uma forma particular de a burguesia reivindicar para si o domínio ideológico da sociedade. Nesse sentido, o destino das lutas por direito está determinado na dinâmica da luta de classes, num complexo jogo que envolve disputas ideológicas quanto à concepção de sociedade e projeto societária que se deseja afirmar. Esse processo não pode prescindir da organização política das classes trabalhadoras nem a estas se limitar, pois, depende de um conjunto de condições objetivas que interferem na história (BEHRING; SANTOS, 2009, p. 280).

Então, torna-se estratégico a luta por direitos, mas tendo-os como meio de viabilização da radicalização da democracia e da cidadania como acentuados no Projeto Ético-Político, não como fim último dessas lutas. Essa complexidade no âmbito da defesa de direitos, coloca um grande nó às determinações objetivas dos/as profissionais e estudantes de Serviço Social, que, muitas vezes, como apontam as falas, reduzem o seu exercício à mera execução de políticas sociais, demarcando o campo dos direitos como fim último de sua intervenção socioprofissional.

É importante demarcar, portanto, que ninguém age sem ter valores, e diante disso, no âmbito profissional também emergem ethos distintos. Essa afirmação nos leva a assegurar que não podemos colocar todas as éticas no mesmo patamar, ao tempo em que não podemos afirmar que outras pessoas não têm ética. Todos os sujeitos profissionais têm um 
ethos, no entanto, esse ethos pode por um lado se sustentar nos valores da sociabilidade vigente ou, por outro lado, enraizar-se em referências humano-genéricas.

\section{CONSIDERAÇÕES FINAIS}

Diante do exposto aqui e também do que foi desenvolvido em nossa dissertação, podemos inquirir algumas análises: a primeira delas, nos leva a apresentar como uma possibilidade que o processo de precarização do ensino superior tem tido rebatimentos no campo de formação profissional, de modo que se assiste a um elevado número de formandos que não ultrapassam, nos termos de Santos (2015), a adesão formal, ao Projeto Ético-Político Profissional.

A segunda consideração é que não há um ethos puro no contexto das relações sociais, o que implica dizer que no âmbito do Serviço Social essa realidade também se confirma. Entretanto, há uma verdadeira reatualização de velhas tendências ético- políticas, as quais não se mostram mais isoladas/separadas, pelo contrário, essas tendências têm se mostrado a partir de uma verdadeira confluência, donde se reatualiza o conservantismo numa perspectiva de modernizar práticas que atendam aos interesses institucionais e sociais postos pelo ethos dominante.

Diante disso, compreendendo a moral e a ética como espaços de suspensão do cotidiano, - Serviço Social vem apostando que a saída dessa realidade encontra sustentação teóricoprática nas diretrizes do Projeto Ético-Político hegemônico na profissão desde meandros dos anos 1980, no entanto, percebe-se pelas falas da sujeitas que a adesão a esse Projeto tem se dado, em sua maioria, na formalidade legal que sustenta tal Projeto, quando alguns sujeitos reduzem o Projeto somente ao instrumental Código de Ética, retirando dele toda a dimensão política e desconhecendo a contradição da luta de classes que o envolve.

Para além da adesão legalista ao Projeto, outro fator que prepondera nessas falas, e que nos preocupa, pois reforça o conservadorismo em sua versão mais reacionária - por meio do discurso religioso - é colocar o projeto como algo bom, ótimo, sem sequer desvelar as mediações presentes nesse processo. Isso leva a uma interpretação de que os valores cristãos da bondade, irmandade, coletivismo religioso, solidariedade, coalização de classes, bem comum, seriam a saída para o contingente das desigualdades sociais postas nessa sociabilidade.

Outra tendência forte desse conservadorismo é a idealização de que o trabalho profissional do/a assistente social poderá emancipar os seus usuários, donde tal tarefa ascende a chama messiânica da profissão, colocando-a em um patamar que não compete a ela, mas sim ao conjunto dos trabalhadores organizados em suas lutas sociais e do conjunto das correlações de forças em cada momento histórico. Diante dessa realidade, acaba-se por idealizar uma ética profissional, retirando dela as bases ontológicas que a compõe, desconectando-a do real, e, colocando-a em um pedestal, como algo abstrato, um tipo ideal a ser seguido, mas que depende da subjetividade de cada sujeito.

Sendo assim, a mera adesão abstrata aos valores profissionais não demarca uma ação ética - na direção do Projeto Ético-Político do Serviço Social -, pelo contrário, demarca a vinculação profissional ao projeto hegemônico de sociedade, o que reafirma o compromisso com o ethos conservador, (re)produzindo o conjunto de valores presentes 
nessa sociabilidade.

E, mesmo apreendendo as condições objetivas e subjetivas que compõem a realidade do/a profissional, não podemos destituí-lo de sua responsabilidade perante o que está posto, mediante as suas ações ético-políticas, pois assim, estaríamos reiterando a própria lógica de fragmentação da vida social, e, por outro lado, desresponsabilizando-o de seus direcionamentos teórico-metodológicos, ético-políticos e técnico- operativos, pois entendemos que as respostas profissionais são sempre uma escolha valorativa dos sujeitos condicionados histórico e socialmente, mas sempre em um processo de liberdade relativa. Esse processo de escolhas traz em si um conjunto de pores teleológicos - como resultado da relação entre causalidade e teleologia, o que coloca ao Serviço Social um conjunto de determinações a priori e posteriori aos processos interventivos.

Logo, o que está conformado é a reatualização do conservadorismo, numa vertente que se adequa aos tempos presentes, que supõe um profissional desqualificado para lidar com políticas públicas desqualificadas, e, com um conjunto de usuários considerados a escória da sociedade contemporânea. Todos esses elementos se reforçam, quando os/as profissionais demonstram, na verdade, sequer conhecer o que é o Projeto Ético-Político da profissão. Todos esses elementos (messianismo, fatalismo, pragmatismo, idealização dos direitos, dicotomia teoria-prática, entre outros) configuram um ethos profissional conservador que mescla diversas expressões de uma única direção, denominada aqui por nós de ethos idealista-formal.

Então, é na agudização das contradições em curso, que esse ethos tem encontrado acento para sua radicalização, o que implica uma tendência de conduzir o exercício profissional, a partir de uma certa racionalidade que balanceia o direcionamento ético- político hegemônico, construído pela profissão nos últimos anos, visto que tal racionalidade, em sua base mais concreta alinha-se ao retorno de tendências reacionárias, consubstanciandose em duas direções, que Guerra (2011) vai denominar, a depender de como se configuram, de racionalismo abstrato-formal ou irracionalismo.

Frente a isso, nos cabe refletir sobre os caminhos que tem se colocado no âmbito profissional e no âmbito da formação e encontrar forças e meios de resistir ao avanço do conservadorismo em todas as suas formas de manifestações.

\section{REFERÊNCIAS}

ANTUNES, Ricardo. Os sentidos do trabalho: ensaio sobre a afirmação e a negação do trabalho. São Paulo: Boitempo, 2003.

BARROCO, Maria Lúcia; TERRA, Sylvia Helena. Código de ética do/a assistente social comentado. São Paulo: Cortez, 2012.

BEHRING, Elaine Rossetti; SANTOS, Silvana Mara Morais dos. Questão social e direitos. Serviço Social: direitos sociais e competências profissionais.Brasília (DF): Conselho Federal de Serviço Social; Associação Brasileira de Ensino e Pesquisa em Serviço Social, 2009. 
ESCORSIM NETTO, Leila. O conservadorismo clássico: elementos de caracterização e crítica. São Paulo: Cortez, 2011.

HARVEY, David. Condição pós-moderna: uma pesquisa sobre as origens da mudança cultural. Trad. Adail Ubirajara Sobral e Maria Stela Gonçalves. São Paulo: Loyola,1993.

HIRSCHMAN, Albert O. A retórica da intransigência. São Paulo: Companhia das Letras, 1992.

GUERRA, Yolanda Aparecida Demétrio. A instrumentalidade do Serviço Social. 9. ed. São Paulo: Cortez, 2011.

GUERRA, Yolanda Aparecida Demétrio. Transformações societárias e Serviço Social: repercussões na cultura profissional In: MOTA, Ana Elizabete; AMARAL, Ângela (Org.). Serviço Social brasileiro nos anos 2000: Cenários, pelejas e desafios. Recife: Editora UFPE, 2014.

IAMAMOTO, Marilda Vilela. Serviço Social em tempo de capital fetiche: Capital financeiro, trabalho e questão social. 8. ed. São Paulo: Cortez, 2014.

IAMAMOTO, Marilda Vilela. Renovação e conservadorismo no Serviço Social: ensaios críticos. 12. ed. São Paulo: Cortez, 2013.

IAMAMOTO, Marilda Vilela; CARVALHO, Raul de. Relações sociais e serviço social no Brasil: esboço de uma interpretação histórico-metodológica. 41. ed. São Paulo: Cortez, 2014.

MARX, Karl; ENGELS, Friedrich. Manifesto do Partido Comunista. Traduzida da edição alemã de 1848. Domínio Público. Disponível em:

<http://www.dominiopublico.gov.br/download/texto/cv000042.pdf>. Acesso em: 30 set. 2018.

NETTO, José Paulo. Lukács: Sociologia. São Paulo: Ática, 1981. (Coleção Grandes Cientistas Sociais, n. 20).

NISBET, R A. Conservadorismo e sociologia. In: MARTINS, José de Souza (Org.). Introdução crítica à Sociologia Rural. São Paulo: Hucitec, 1981.

PONTES, Reinaldo Nobre. Mediação e Serviço Social: um estudo preliminar sobre a categoria teórica e apropriação pelo Serviço Social. 7. ed. São Paulo: Cortez, 2010.

SADER, Emir; GENTILI, Pablo (Orgs.). Pós-neoliberalismo: as políticas sociais e o Estado democrático. Rio de Janeiro: Paz e Terra, 2010.

SANTOS, Silvana M. de S. Módulo: Ética e direitos humanos. XIX Curso Ética em movimento. São Paulo: Conselho Federal de Serviço Social, 2015.

TOSCANO, Moema; GOLDENBERG, Mirian. A revolução das mulheres: um balanço do Feminismo no Brasil. Rio de Janeiro: Revan, 1992. 
WEBER, Max. Ciência e política: duas vocações. Trad. Leônidas Hegenberg e Octany Silveira da Mota. 4. ed. Brasília (DF): Universidade de Brasília; São Paulo: Cultrix, 1983. 